\title{
Analyzing Student Satisfaction in the Technical and Vocational Education System through Collaborative Teaching
}

\author{
Shiow-Luan Wang ${ }^{1, *}$, Hsiou-Ping Chen ${ }^{2}$, Shiow-Lin $\mathrm{Hu}^{3}{ }^{3}$ and Chien-Ding Lee ${ }^{4}$ \\ Department of Information Management, National Formosa University, Yunlin 632, Taiwan \\ Principal's Office, National Sun Yat-Sen University, Kaohsiung 811, Taiwan \\ Department of Digital Multimedia Design, National Taipei University of Business, Taipei 100, Taiwan \\ 4 Department of Information Systems, Changhua Christian Hospital, Changhua 50006, Taiwan \\ * Correspondence: slwang@nfu.edu.tw; Tel.: +886-933-173-886
}

Received: 12 August 2019; Accepted: 2 September 2019; Published: 5 September 2019

\begin{abstract}
The sustainable development of science and environmental education is a core mechanism in the world education system. The implementation of the goal of establishing science and environmental education comprehensively in higher education, especially in vocational education, poses a challenge. Basic vocational education is a category of the education system, as well as sustainable development, which involves the technical and vocational education (TVE) system (20-30 general/compulsory/elective credits required). Awareness of the sustainable development in science and environment is getting more and more emphasized by educators. For students' learning to use, it was recommended that universities use education for sustainable development (ESD) in TVE programs. This study proposes clarifying whether anticipating the needs of TVE university students is more conducive for them. Also, for the global understanding about innovative education, the "awareness of the sustainable development in science and environment" was involved in our experimental items. The learning satisfaction derived from students from the collaborative teaching of the industry experts in the TVE system is another point of focus. Students who take the course attend six weekly three-hour periods in class. An e-learning system is utilized so that learning resources created by industry experts can be provided. The deployment facilitates the evaluation of basic vocational education because teaching is not only performed in a traditional class but also prompted via a valuable e-learning system. The results showed that "Level of respect during the collaborative teaching of industry experts" (mean $=3.93$; S.D. $=0.751$ ) was rated by students as satisfactory and "Overall efficiency of teaching materials" (mean $=3.47$ ) was rated as the lowest of the items. "Awareness of the sustainable development in science and environment" (mean = 3.86; S.D. $=0.752$ ) was rated by students as highly satisfactory. To verify the result, an analysis of the improvement of learning satisfaction is discussed. Practical implications and future work are also discussed.
\end{abstract}

Keywords: science and environmental education; basic vocational education; learning satisfaction; collaborative teaching

\section{Introduction}

Education is a continuous and life-long process. Education for sustainable development (ESD) is fundamentally about the links between the awareness of the human as a whole in nature and its supporting social systems and the health of the planet, which we inhabit, with responsibilities for the present and future world [1]. Technical and vocational education (TVE) is an educational provision that mainly focuses on the sustainable development of science and the environmental education of 
workers with skills in professional technology. For the last half-century, the TVE educational system has contributed to the transformation and growth of economic power. The technical workforce requires a labor force with practical skills and knowledge. In this respect, the TVE system plays an important role in supporting national development, long-term growth, and international interaction $[2,3]$.

More than traditional theoretical education, the TVE education system focus on the development of practical techniques for specific domains. A variety of work categories relies on supporting the TVE education system, especially for those who have to receive long-term and practical technique training, such as an engineer, architect, accountant, chef, and so on. For instance, an information engineer is a professional career and must have sufficient proficient ability for building information systems by programming code or maintaining hardware/network equipment, respectively. Thus, the best way to understand how to do it is to listen to real experience and practice it practically rather than merely read a lot of books.

The TVE system can be regarded as technical training or career education because it mainly aims at developing practical skills as the core of its objectives. Despite theoretical teaching and basic technical exercise, TVE students lack practical experience, which is mainly derived from actual industry practice. This educational gap exists due to the gap between school and industry. In this context, the educational process remains ineffective although students receive the skills necessary for a qualified worker.

Gaining experience in real industry operations at an early stage in the educational process is important for TVE students for two major reasons. First, the career that the individual prefers can be explored by taking the requirements and comprehensive evaluation into account. Such exploration also facilitates career development because students can be exposed early to industrial properties, challenges, benefits, and responsibilities for the job position. Additional advanced skills, which require long-term training, can be prepared as early as possible to qualify for a certain position. Second, students maximize their practical experience because a means is established for realizing problems that may be encountered in their position in the future. As a result, the possibility of meeting future conflicts and disappointments in career development can be minimized.

Evaluating basic vocational education will closely meet the requirements of the real industry while the student is still in school [4]. To achieve this objective, Taiwanese educational institutes and universities have exerted immense effort [3,5] by issuing educational policies based on an industry-university cooperative plan. For instance, industry expert collaborative teaching (IECT) is a policy which has been promoted for several years now in the TVE system. Through inviting industry experts from various industries, training in terms of professional skills and knowledge can be integrated into daily teaching to fill the gap between school and industry; that is, instruction is achieved with industry-academy cooperation. Although IECT is beneficial to the TVE system, a challenge is posed with the introduction of the IECT method. Specifically, integrating lessons and real industry concerns is a crucial element but it is weak in typical IECT. To improve the effectiveness of IECT, a tight connection between the school and industry is a necessity.

According to the information published by the Ministry of Education, over 50 percent of high school students in Taiwan are learning in the TVE system [6]. Table 1 summarizes the statistical data at the high-school level to compare the situations of regular and vocational schools and students.

In this study, we introduce a new method based on Taiwanese IECT to address the concerns of TVE by providing two major parts. First, rather than a traditional discussion and workshop, a long-term integrated teaching method is implemented, which includes introducing the industry and practicing the required skills. Furthermore, we aim to clarify whether a conducive means of anticipating the needs of TVE university students is viable and achieves good learning satisfaction through the collaborative teaching of industry experts in the TVE system in Taiwan. 
Table 1. Number and percentage of regular and vocational high schools and students in Taiwan.

\begin{tabular}{ccccccccc}
\hline & \multicolumn{7}{c}{ N } & \multicolumn{2}{c}{$\%$} \\
\cline { 2 - 8 } Year & $\begin{array}{c}\text { Senior } \\
\text { High } \\
\text { Schools }\end{array}$ & $\begin{array}{c}\text { Regular } \\
\text { High } \\
\text { Schools }\end{array}$ & $\begin{array}{c}\text { Vocational } \\
\text { High } \\
\text { Schools }\end{array}$ & $\begin{array}{c}\text { High School } \\
\text { Students } \\
\text { (Regular and } \\
\text { Vocational) }\end{array}$ & $\begin{array}{c}\text { Regular } \\
\text { High } \\
\text { School } \\
\text { Students }\end{array}$ & $\begin{array}{c}\text { Vocational } \\
\text { High } \\
\text { School } \\
\text { Students }\end{array}$ & $\begin{array}{c}\text { Regular High } \\
\text { School } \\
\text { Students (\%) }\end{array}$ & $\begin{array}{c}\text { Vocational } \\
\text { High School } \\
\text { Students (\%) }\end{array}$ \\
\hline 2017 & 508 & - & - & 797,281 & 357,436 & 439,845 & 44.83 & 55.17 \\
2016 & 503 & - & - & 829,313 & 364,196 & 465,117 & 43.92 & 56.08 \\
2015 & 503 & - & - & 846,051 & 369,337 & 476,714 & 43.65 & 56.35 \\
2014 & 500 & - & - & 873,159 & 379,000 & 494,159 & 43.41 & 56.59 \\
2013 & 499 & 344 & 155 & 917,122 & 396,375 & 520,747 & 43.22 & 56.78 \\
2011 & 495 & 340 & 155 & 947,632 & 406,187 & 541,445 & 42.86 & 57.14 \\
\hline
\end{tabular}

In our design, students who take the course attend six three-hour classes weekly. Industry experts are invited to tie in with the course, thus combining theoretical guidance and practical experience. An e-learning system is employed throughout the period, such that the learning resource created by industry experts is easily and effectively accessed. Interaction among the participants, namely industry experts, instructors, and students, can be conveniently achieved by applying a mature e-learning system, which is a crucial factor for the improvement of learning effectiveness.

The remainder of this paper is organized as follows. First, we briefly review the related literature into the study of basic vocational education and IECT to facilitate the realization of the research. The methodology section describes the proposed method in detail to improve IECT. The results and experimental design sections, respectively, provide the result and experimental design to demonstrate the contribution of this paper, and the final section provides a discussion and concludes the paper.

\section{Related Studies}

\subsection{Sustainable Development of Science and Environmental Education}

Aiming toward a sustainable future, Education for Sustainable Development (ESD) is valuable for promoting people to change their way of thinking and working [7]. Since 1992, ESD has been developed and has become a well-established aspect of education [8,9]. In the UN, 17 goals for sustainable development have been developed. For education purposes, Goal 4 is designed to ensure inclusive and equitable quality education and promote lifelong learning opportunities for all. Moreover, technical and vocational education, relevant skills, job employment, and persons with disabilities are also involved in goals 4.3 to 4.5 [10]. After graduation from school education, workers take the necessary actions to control their situation based on the feedback of learning before and after acting with each other. Science and environmental education is an important intellectual asset to a firm. Therefore, a firm is hoping to gather their workers' skill, intelligence, experience, and capability as a knowledge repository.

\subsection{Basic Vocational Education}

Basic vocational education is a category of education in several countries. In contrast to regular education, the vocational educational system mainly aims to mold an individual to obtain recognized profitable employment [11]. Another benefit of this system is that promoting vocational education decreases the overall employment rate with an increase in vocational education students [2]. This mechanism builds a platform on which to balance the supply and demand for employees and enterprises. Therefore, vocational education is regarded as an economic asset that generates profit for the country, especially for new employees who are derived from the vocational education system [12]. The new employees, however, are required to have strong adaptability, multiple skills, and creativity [13]. To fulfill the competency levels required by the workplace, students should receive quality vocational education [12]. Various bodies of research proposed the enhancement 
of vocational education in terms of strategy, study content, and instruction [14-16]. Among these concerns, solving the gap between industry and study content as offered by schools remains crucial due to its influence in career development.

\subsection{Industry Expert Collaborative Teaching}

Mentorship, a relationship in which people with experience lead people with less experience for the growth of knowledge, wisdom, or technology, is a popular traditionally method, especially in the technological and vocational education domains. Advantages, such as good communication, personalization, effectiveness, and rapid adjustment are gained through this process. Mentoring is currently the major trend in vocational education. It aims to supply superior professional preparation and career evaluation prior to formal employment. Compared with an industry expert, full-time teachers have less field experience because they mainly focus on curriculum and instruction in school. Without experience in the actual industry, effectively accommodating further changes and tendencies remains a challenge $[16,17]$

Recently, IECT has become a well-established policy and has been gaining increased attention from the TVE system in Taiwan. IECT is a feasible option because it not only enhances student competency, but also improves full-time teachers' mastery of the industry.

Aside from the professionalism of industry experts, a willingness to share knowledge is an essential factor for learning effectiveness. Thus, evaluating an industry expert's passion and willingness is a top priority when employing experts for collaborative teaching [4]. According to previous research, IECT performance depends on five criteria, namely value, career sharing, learning benchmark, extension of the individual and international viewpoint, and the promotion of career development $[17,18]$. Therefore, in this present work, several of the above-mentioned criteria will be used to evaluate the adaption of industry experts.

\section{Methodology of Research}

In February 2017, a survey of enrolled university college students was conducted to collect data about students' perspectives and learning satisfaction regarding the use of IECT. The questionnaire was related to the awareness provided by industry experts, the use of services and resources offered, and their perspectives on the IECT program. These items were formulated to ascertain the perspectives, expectations, and general informational needs of students. This section describes the design of the survey instrument and the methods used for developing and administering the survey.

\subsection{Participants}

Students who enrolled in the "Management" course in the fall of the 2016 academic year were invited to join the IECT in class. The manner of creating information was discussed, and students were tasked to select a topic, search for information and cite available resources and links on the medical web to access information (simultaneous remote access across multiple databases, seamless links to database resources, and email alert set-up). Topics, such as the types of collaborative teaching, understanding information technology skills in the medical industry, and effective searches were discussed. All instructions were developed by considering the students' need for workplace exploration.

\subsection{Questionnaire Development}

The learning satisfaction questionnaire is composed of four constructs: teaching material, teaching methods, interpersonal relationships, and workplace exploration (Figure 1). Each scale was scored using a five-point Likert scale ranging from "always" (5) to "not at all" (1). All items were presented according to their order of importance in the teaching environment: teachers, learners, program, and the teaching environment. 


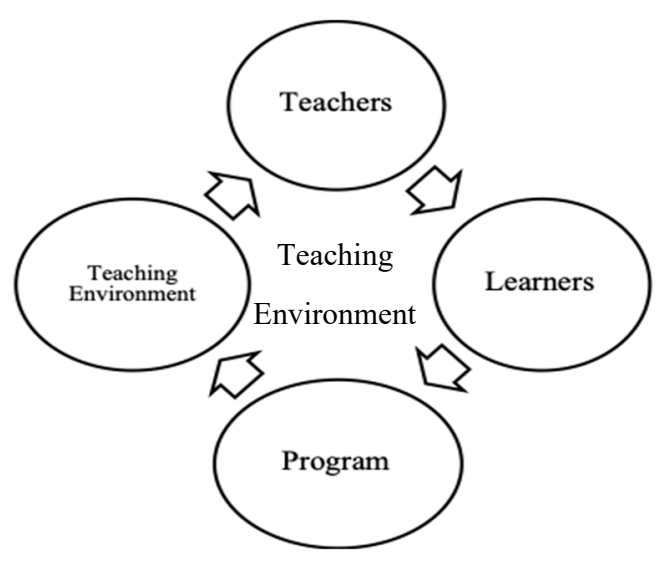

Figure 1. Main body in teaching environment.

We included the item "workplace exploration" in the questionnaire because the IECT was conducted as a main issue in class. Therefore, we expect the industry experience and workplace capability of the experts to be integrated into the learning program. Additionally, we offered three open-ended questions in which students were free to give their opinion. These qualitative data generalize a conclusion after induction and consolidation as triangulation in the quantitative questionnaire.

\subsection{Pilot Study}

To collect data on learning satisfaction, we conducted a preliminary draft of the pre-test questionnaire through the literature review and relevant studies. Testing for construct validity was conducted by two experts after revising the content. The pre-test questionnaires were distributed to students of the National University of Science and Technology who shared the same background as that of our research subjects. These pre-test students received at least two sessions of three-hour professional teaching courses.

This survey was conducted in February 2017. The participants comprised students who took the course in their third and fourth years of university. These students had a collaborative teaching course during the semester, and each took only one course and completed one questionnaire. We received 24 valid questionnaires out of the 25 initial surveys after considering one questionnaire as invalid.

\section{Measures}

\subsection{Measures for Constructs}

We aimed to use valid and reliable measures. A preliminary analysis of the responses addressed the external and construct validities and reliability of the study. The external validity was assessed, and factor analysis was conducted to examine the structural validity of the measure. We used the following methods to measure the statistics in terms of the teaching materials, teaching methods, interpersonal relationship, and workplace exploration constructs.

\subsection{Factor Analysis (Construct Validity) and Reliability Analysis (Cronbach's Alpha)}

Factor analysis was performed with the Kaiser-Meyer-Olkin measure of sampling adequacy. The cumulative variation of the four eigenvalues was 66.727 .

Cronbach's alpha [19] was calculated to assess the measurement reliability. Alpha values will be high if the various items that constitute the construct are strongly correlated with each other. A Cronbach's alpha of $\geq 0.70$ is judged to represent high internal consistency [20]. The reliability of the questionnaire was tested by Cronbach's alpha. The overall alpha coefficient of the questionnaire was 0.975. The four constructs of reliability were $0.951,0.935,0.918$, and 0.929 for teaching material, teaching methods, interpersonal relationship, and workplace exploration, respectively. Thus, these items have acceptable reliability and validity for testing the research questions, and the sample is adequate. 


\section{Experimental Design}

\subsection{Intervention of Learning Program}

The study is designed to use a control group time-series in time-series analysis to implement a 16-week course from September 2016 to January 2017. Four course segments were carried out within 16 weeks. In each segment, teachers and industry experts conducted collaborative teaching. The course teachers played the role of teaching aides during the lectures given by the industry expert. Thus, both parties improved their personal learning and further understood the learning needs of students. The teacher and program arrangement are shown in Tables 2 and 3.

Table 2. Teacher arrangement.

\begin{tabular}{cccccc}
\hline & $\mathbf{T}_{1}$ & $\mathbf{T}_{2}$ & $\mathbf{T}_{3}$ & $\mathbf{T}_{4}$ & $\mathbf{T}_{5}$ \\
\hline & 2 Weeks & 2 Weeks & 4 Weeks & 4 Weeks & 4 Weeks \\
\hline $\begin{array}{l}\text { Course teacher } \\
\text { Industry expert }\end{array}$ & $\bigcirc$ & & $\bigcirc$ & & $\bigcirc$ \\
\hline
\end{tabular}

Table 3. Program arrangement.

\begin{tabular}{cc}
\hline & Instruction Content \\
\hline $\mathrm{T}_{1}$ & Basic knowledge of management (part 1) \\
$\mathrm{T}_{2}$ & Application of management in the medical industry and industry workplace capability \\
$\mathrm{T}_{3}$ & Basic knowledge of management (part 2) \\
$\mathrm{T}_{4}$ & Needs of capability in information-technology related management in the medical industry \\
$\mathrm{T}_{5}$ & Project organization and training \\
\hline
\end{tabular}

\subsection{Participants}

This study adopted a purposive sampling method for the sample, namely students from the National University of Science and Technology.

\subsection{Data Collection}

This survey was conducted in September $2016\left(\mathrm{~T}_{5}\right)$. The respondents consisted of third and fourth-year students of the university who enrolled in a collaborative teaching course during the semester. Each student took only one course and completed only one questionnaire. The number of questionnaires was 45 out of 46 after eliminating one with the missing values (invalid).

\section{Data Analysis}

After the satisfaction analysis, the mean score was 3.69 with a standard deviation of 0.91 . $t$-tests were computed on the mean values to examine whether significant differences existed between respondents. To investigate whether the average numbers of constructs and items were significantly different from the average number of samples (assuming that the average number of the population is set to 3.5 (test value $=3.5$ )), this study retains a single sample $t$-test. No significant difference was found at the $95 \%$ confidence level, which indicates the absence of bias.

Tables 4 and 5 illustrate that the four constructs reached a significant level after a one-sample $t$-test with a positive $t$ value. They provide the mean and standard deviations regarding the students' perspectives of the management course. The mean scores for each construct were as follows: "course materials" $(\mathrm{M}=3.56)$, "teacher training" $(\mathrm{M}=3.76)$, "interpersonal relationships" $(\mathrm{M}=3.91)$, and "workplace tests" $(\mathrm{M}=3.77)$. In addition to "course materials," satisfaction in terms of other constructs was positive. 
Table 4. Mean and standard deviation of constructs.

\begin{tabular}{|c|c|c|c|c|c|}
\hline & Construct & Participants & Mean & $\begin{array}{l}\text { Standard } \\
\text { Deviation }\end{array}$ & $\begin{array}{c}\text { One-Sample } \\
t \text {-Test }(M>3.5)\end{array}$ \\
\hline A & Teaching material & 45 & 3.56 & 0.891 & 0.418 \\
\hline $\mathrm{B}$ & Teaching methods & 45 & 3.76 & 0.761 & $2.307 *$ \\
\hline $\mathrm{C}$ & Interpersonal relationship & 45 & 3.91 & 0.744 & $3.706^{* * *}$ \\
\hline $\mathrm{D}$ & Workplace exploration & 45 & 3.77 & 0.771 & 2.339 * \\
\hline $\mathrm{E}$ & $\begin{array}{l}\text { Awareness of the sustainable development } \\
\text { in science and environment }\end{array}$ & 45 & 3.86 & 0.752 & $3.611^{* * *}$ \\
\hline
\end{tabular}

Table 5. Mean and standard deviation of items.

\begin{tabular}{|c|c|c|c|c|}
\hline & Items & Mean & S.D. & $\begin{array}{l}\text { One-Sample } \\
t \text {-Test }(\mathrm{M}>3.5)\end{array}$ \\
\hline A1 & The teaching materials are substantial and detailed. & 3.69 & 0.793 & 1.599 \\
\hline A2 & The teaching materials are practical. & 3.58 & 0.892 & 0.585 \\
\hline A3 & The class hours are appropriately allocated. & 3.53 & 1.057 & 0.211 \\
\hline A4 & Degree of difficulty of teaching materials. & 3.53 & 1.036 & 0.216 \\
\hline A5 & Learning method of problem solving of teaching materials. & 3.53 & 0.919 & 0.243 \\
\hline A6 & Overall efficiency of teaching materials. & 3.47 & 0.842 & -0.266 \\
\hline B1 & I was interested in the industry experts. & 3.60 & 0.863 & 0.777 \\
\hline B3 & Teaching attitude of industry experts. & 3.84 & 0.767 & $3.011 * * *$ \\
\hline B4 & Professional capability of industry experts. & 3.93 & 0.809 & $3.593 * * *$ \\
\hline B5 & Teaching methods for the digital learning platform of industry experts. & 3.76 & 0.802 & $2.137^{* *}$ \\
\hline B6 & Teaching methods of the collaborative teaching of industry experts. & 3.71 & 0.727 & 1.948 \\
\hline B7 & Overall teaching efficiency of industry experts. & 3.82 & 0.806 & $2.682 *$ \\
\hline $\mathrm{C} 1$ & My participation in the collaborative teaching of industry experts. & 3.93 & 0.780 & $3.725^{* * *}$ \\
\hline $\mathrm{C} 2$ & $\begin{array}{l}\text { My participation with other team members in the collaborative teaching } \\
\text { of industry experts. }\end{array}$ & 4.02 & 0.753 & $4.65^{* * *}$ \\
\hline $\mathrm{C} 3$ & Communication and interaction with industry experts. & 3.73 & 0.780 & 2.006 \\
\hline $\mathrm{C} 4$ & Level of respect during the collaborative teaching of industry experts. & 3.93 & 0.751 & $3.872 * * *$ \\
\hline $\mathrm{C} 5$ & Overall relationship in the collaborative teaching of industry experts. & 3.93 & 0.837 & $3.474 * * *$ \\
\hline D1 & $\begin{array}{l}\text { Top learning methods in different fields through collaborative teaching } \\
\text { of industry experts. }\end{array}$ & 3.84 & 0.767 & $3.011 * * *$ \\
\hline D2 & $\begin{array}{l}\text { I was stimulated by various thinking methods during the collaborative } \\
\text { teaching of industry experts. }\end{array}$ & 3.84 & 0.737 & $3.134 * * *$ \\
\hline D3 & $\begin{array}{l}\text { I gained increased knowledge on industry needs in terms of } \\
\text { human resources. }\end{array}$ & 3.78 & 0.850 & $2.193 *$ \\
\hline D4 & $\begin{array}{l}\text { I gained confidence in creating or developing myself in terms of } \\
\text { industry needs. }\end{array}$ & 3.64 & 0.857 & 1.131 \\
\hline D5 & My overall workplace exploration. & 3.73 & 0.837 & 1.871 \\
\hline E1 & Awareness of the sustainable development in science and environment & 3.86 & 0.752 & $3.611 * * *$ \\
\hline
\end{tabular}

Of the constructs under teaching materials, the items A1: "The teaching materials are substantial and detailed" (mean = 3.69; S.D. $=0.793)$, A2: "The teaching materials are practical" (mean = 3.58; S.D. = 0.892), and A3: "Class hours are appropriately allocated" (mean = 3.53; S.D. = 1.057) were rated by students as highly satisfactory. 
Of the constructs under teaching methods, the items B4: "Professional capability of industry experts" (mean = 3.93; S.D. = 0.809), B3: "Teaching attitude of industry experts" (mean = 3.84; S.D. $=0.767$ ), and B5: "Teaching methods for the digital learning platform of industry experts" $($ mean $=3.76$; S.D. $=0.802)$ were rated by students as highly satisfactory.

Of the constructs under interpersonal relationships, the items C2: "My participation with other team members in the collaborative teaching of industry experts" (mean $=4.02$; S.D. $=0.753$ ), C1: "My participation in the collaborative teaching of industry experts" (mean $=3.93$; S.D. $=0.780$ ), and C4: "Level of respect during the collaborative teaching of industry experts" (mean $=3.93$; S.D. $=0.751$ ) were rated by students as highly satisfactory.

Of the constructs under workplace exploration, the items D1: "Top learning methods in different fields by the collaborative teaching of industry experts" (mean $=3.84$; S.D. $=0.767$ ), D2: "I was stimulated by various thinking methods by the collaborative teaching of industry experts" (mean $=3.84$; S.D. = 0.737), and D3: "I gained increased knowledge of industry needs in terms of human resources" (mean $=3.78$; S.D. $=0.850$ ) were rated by students as highly satisfactory.

Of the constructs under awareness of the sustainable development in science and environment, the items E1 "Awareness of the sustainable development in science and environment" (mean = 3.86; S.D. $=0.752$ ) were rated by students as highly satisfactory.

The Items A6: "Overall efficiency of teaching materials" (mean = 3.47) was rated as the lowest of the items. Notably, students are less in contact with the industry expert and are unclear as to whether the expert is beneficial for them. This will be improved by decreasing the sense of conflict of students with the description of the lecturers during the early stages.

\section{Conclusions}

We found that students experience learning satisfaction in terms of teacher training, such as teaching methods, interpersonal relationships, and workplace exploration. The result for workplace exploration is consistent with previous research [15,21]; that is, industry experts possess ample professional knowledge of the workplace. Students were mainly concerned about three items under the workplace exploration construct, namely "Top learning methods in various fields by the collaborative teaching of industry experts," "I was stimulated by different thinking methods by the collaborative teaching of industry experts," and "I gained improved knowledge on industry needs in terms of human resources." Notably, industry experts can impart knowledge to and stimulate another type of learning for students. These conclusions will help us revisit our priorities for students in terms of the relative efforts in receiving industrial knowledge. The mean score of item "Awareness of the sustainable development in science and environment is 3.86, we can see that students hopefully have the knowledge of ESD from the learning process; such situations are usually ignored by the education system. It is highly recommended that the TVE program is reoriented by utilizing appropriate models and best practices from other institutions in nations who have successfully refocused their TVE program for sustainability [22]. We further provided implications and directions for future studies.

The impact of using IECT in basic vocational education for TVE, the ability to communicate and share knowledge, and the professional knowledge of industry experts are extremely important [4]. The current study adopts the method of collaborative teaching between course teachers and industry experts in a classroom setting. Our findings can provide students with an enhanced quality of teaching due to integrated education. We suggest that educators pay increased attention to teaching content and professional fields in TVE in the future.

Author Contributions: Conceptualization, all authors; methodology, formal analysis, and data extraction, S.-L.H.; writing — original draft preparation, C.-D.L.; writing—review and editing, S.-L.W.; visualization, H.-P.C.; supervision, S.-L.W.

Funding: This research received no external funding.

Conflicts of Interest: The authors declare no conflict of interest. 


\section{References}

1. Shohel, M.M.C.; Howes, A.J. Models of Education for Sustainable Development and Nonformal Eduction: A Bangladeshi Perspective. J. Educ. Substain. Dev. 2011, 5, 1-11.

2. Blinovaa, T.; Bylinaa, S.; Rusanovskiyb, V. Vocational Education in the System of Determinants of Reducing Youth Unemployment: Interregional Comparisons. Procedia Soc. Behav. Sci. 2015, 214, 526-534. [CrossRef]

3. Ministry of Education, Technological \& Vocational Education in Taiwan, ROC, August 2011. Available online: http://english.moe.gov.tw/public/Data/New182910424171.pdf (accessed on 1 August 2019).

4. Chen, W.-Y. The Influence of Team-Teaching Program to Student' Practical Learning Efficiency at Technological College. J. Sci. Technol. Humanit. Transw. Univ. 2014, 18, 35-47.

5. Ministry of Education. The Vocational Education Reengineering Plan. 2013. Available online: https: //www.iaci.nkfust.edu.tw/Industry/CP.aspx?s=130\&n=129 (accessed on 1 August 2019).

6. Ministry of Education Statistics Division. 2018. Available online: https://stats.moe.gov.tw/high/ (accessed on 15 August 2019).

7. UNESCO. Education for Sustainable Development. 2019. Available online: https://en.unesco.org/themes/ education-sustainable-development (accessed on 24 July 2019).

8. Wals, A. A Mid-DESD Review: Key Findings and Ways Forward. J. Educ. Sustain. Dev. 2009, 3, $195-204$. [CrossRef]

9. Wright, T.S.A.; Pullen, S. Examining the Literature: A Bibliometric Study of ESD Journal Articles in the Education Resources Information Center Database. J. Educ. Sustain. Dev. 2007, 1, 77-90. [CrossRef]

10. UNITED NATIONS. Open Working Group Proposal for Sustainable Development Goals. 2019. Available online: https://sustainabledevelopment.un.org/focussdgs.html (accessed on 24 July 2019).

11. Ram, T. Role of Vocational Education; Global Media: London, UK; England, UK, 2009.

12. Munastiwi, E. The Management Model of Vocational Education Quality Assurance Using 'Holistic Skills Education. Procedia Soc. Behav. Sci. 2015, 204, 218-230. [CrossRef]

13. Rudenko, D.; Morosova, E. Prospects for the Development of Further Vocational Education in the Tyumen Region of Russia. Procedia Soc. Behav. Sci. 2015, 214, 693-699. [CrossRef]

14. McCleary, K.W.; Weaver, P.A. The effective use of guest speakers in the hospitality and tourism curriculum. J. Teach. Travel Tour. 2008, 8, 401-414. [CrossRef]

15. Alan, N. The Role of Technical Vocational Education and Training in Human Development: Pakistan as a Reference Point. Eur. Sci. J. 2015, 11, 35-50.

16. Hsu, C.H.; Feng, L.Y.; Chiang, M.-H.; Su, Y.-H. A Study on the Effect and the Related Factors of Academia-Industry Cooperative Teaching in Hospitality Education. NPUST Humanit. Soc. Sci. Res. Pedagog. 2016, 10, 30-59.

17. Feng, L.Y.; Su, Y.H.; Yang, C.C.; Hsu, C.H. University hospitality teachers' industry experiences and their influences on university teaching practices in the classroom. Int. J. Asian Tour. Manag. 2012, 3, 111-122.

18. Yen, P.-R.; Wen, L.-Y. Research on Teaching Strategies and Learning Achievements of Collaborative Teaching. Pulse Educ. 2016, 8, 4-41. Available online: https://pulse.naer.edu.tw/Home/Content/adec4179-f0be-4a329381-4641f6491838?insId=caf63afc-36f5-4945-bc5d-0189edf5c486 (accessed on 25 September 2018).

19. Cronbach, L.J.; Meehl, P.E. Construct validity in psychological tests. Psychol. Bull. 1955, 52, 52-281. [CrossRef]

20. Nunnally, J.C. Psychometric Theory; McGraw-Hill: New York, NY, USA, 1978.

21. Ruhanen, L. Bridging the divide between theory and practice: Experiential Learning approaches for tourism and hospitality management education. J. Teach. Travel Tour. 2005, 5, 33-51. [CrossRef]

22. Chinedu, C.C.; Mohamed, W.A.W.; Ajah, A.O. A Case Analysis of the Visibility of Sustainability in a TVE Teacher Training Program: Evidence from the Program Curriculum of an HEI. Traektoriâ Nauk. Path Sci. 2018, 4, 5001-5011. [CrossRef]

(C) 2019 by the authors. Licensee MDPI, Basel, Switzerland. This article is an open access article distributed under the terms and conditions of the Creative Commons Attribution (CC BY) license (http://creativecommons.org/licenses/by/4.0/). 